\title{
Cystic lung disease in an adult non-smoker
}

\section{Ambarish Joshi, Nitesh Gupta, Pranav Ish, Shibdas Chakrabarti}

VMMC and Safdarjung Hospital, New Delhi, India

A 33-year-old non-smoking male who was a farmer by trade and had no other comorbidities presented with complaints of shortness of breath, left sided chest pain and dry cough which had bothered him for over the past 7 days. Past history was insignificant. The patient had tachycardia, tachypnoea (30/min) and oxygen saturation of $88 \%$. There was no clubbing or cyanosis. Chest examination was suggestive of bilateral decreased air entry. A CT examination of the chest was performed (Figure 1A, B). Bilateral intercostal chest tubes were inserted and the patient was given oxygen support. Due to refusal by the patient to perform a surgical lung biopsy, a trans-bronchial lung biopsy (TBLB) (Figure 1C, D) was performed. The patient had bilateral leaks in intercostal chest tubes. When negative suction to both sides was applied, successful cessation of the air leaks was observed.

As the CT thorax was suggestive of bilateral pneumothorax with underlying cysts predominantly in upper and mid zones, few nodular opacities, and sparing of costophrenic recess, a provisional diagnosis of pulmonary Langerhans cell histiocytosis (pLCH) was suspected. Transbronchial lung biopsy was suggestive of interstitial fibrosis with a collection of Langerhans cells that had prominent nuclei with CD1a positivity. Thus, the diagnosis of pLCH was made on the basis of clinico-radiological, histopathological and immunohistochemical grounds.

According to an expert panel, definitive diagnosis of pLCH requires either microscopic evidence of Langerhans cells with CD1a positivity or Birbeck granule visualization on electron microscopy [1].

A detailed history of polyuria, polydipsia, headache, bone pains, diarrhoea, weight loss, enlarged lymph nodes, oral/skin lesions and/or genital ulcers was negative. Liver function tests, a routine examination of urine for sugar and proteins, ultrasonography of the abdomen and pelvis, a CT examination of the head, and a skeletal scintigram (bone scan) were all normal.

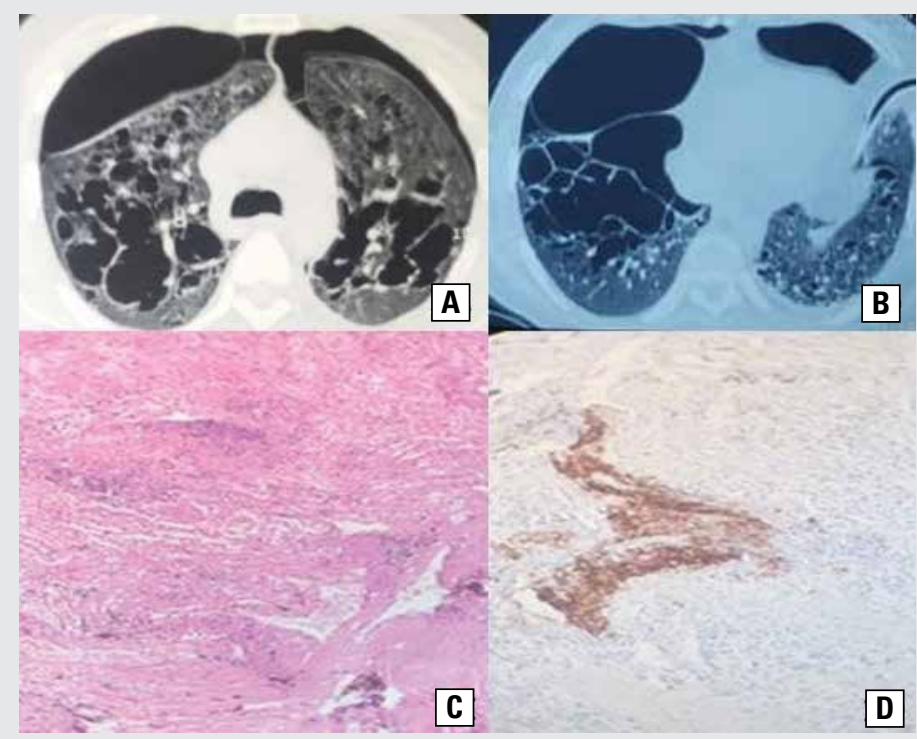

Figure 1. A, B. Contrast enhanced CT chest showing bilateral pneumothorax with bilateral well defined, irregular, thin walled bizarre cysts of variable shape and size with a predominance in the upper and middle lobes. There is sparing of the costophrenic angles; C. Transbronchial lung biopsy $(10 \times$ magnification in hematoxylin and eosin stain) showing sheets of Langerhans cells with prominent nucleoli which were positive for CD1a (D)

Address for correspondence: Pranav Ish, VMMC and Safdarjung Hospital, New Delhi, India; e-mail: pranavish2512@gmail.com DOI: 10.5603/ARM.2019.0066

Received: 3.08 .2019

Copyright (C) 2019 PTChP

ISSN 2451-4934

Conflict of interest: none declared 
pLCH has an association with smoking in 95\% of patients. However, it has been reported in non- smokers also [2,3]. Our patient had never smoked tobacco or marijuana. This rarity may be a cause of the delayed diagnosis.

Smoking cessation has been shown to be partially effective in preventing progression [4], but it is not always beneficial [5]. Treatment in non-smokers can be given if the patient is symptomatic. Steroids have been shown to be beneficial in pLCH, especially in isolated pulmonary involvement in adults. Cladribine has also been tried in non-responsive cases [6]. Cases of pneumothorax are treated with standard measures which include, among others, intercostal drainage via tubes with pleurodesis. Pleurectomy should be avoided as patients will eventually need a lung transplant in progressive cases. Our patient is on oral $1 \mathrm{mg} / \mathrm{kg}$ prednisolone therapy as recommended by an expert panel [1]. Watchful waiting was not preferred as our patient continued to be symptomatic. However, in view of an absence of any randomized trials for steroid therapy in $\mathrm{pLCH}$, the therapy must be weighed on the basis of risk-benefit ratio as patients with spontaneous remission have also been reported [1]. The patient has been counseled for the future need of a lung transplant. Five-year survival has been reported to be more than $50 \%$, but post-transplant recurrence has also been shown in $20 \%$ of patients [6].

Thus, it is prudent to search for pLCH even in non-smoking young adult males, particularly in patients with collaborative radiological and pathological evidence. This is true because, even in such rare cases, an early diagnosis can help in early treatment and in providing an improved prognosis.

\section{References:}

1. Girschikofsky M, Arico M, Castillo D, et al. Management of adult patients with Langerhans cell histiocytosis: recommendations from an expert panel on behalf of Euro-Histio-Net. Orphanet J Rare Dis. 2013; 8: 72, doi: 10.1186/1750-1172-8-72, indexed in Pubmed: 23672541.

2. Tadokoro A, Ishii T, Bandoh S, et al. Pulmonary langerhans cell histiocytosis in a non-smoking japanese woman. Nihon Kokyuki Gakkai Zasshi. 2011; 49(3): 203-207, indexed in Pubmed: 21485154.

3. Shen J, Feng S. Bone Langerhans cell histiocytosis with pulmonary involvement in an adult non-smoker: A case report and brief review of the literature. Mol Clin Oncol. 2017; 6(1): 67-70, doi: 10.3892/mco.2016.1077, indexed in Pubmed: 28123731.

4. Suri HS, Yi ES, Nowakowski GS, et al. Pulmonary langerhans cell histiocytosis. Orphanet J Rare Dis. 2012; 7: 16, doi: 10.1186/17501172-7-16, indexed in Pubmed: 22429393.

5. Tazi A. Adult pulmonary Langerhans' cell histiocytosis. Eur Respir J. 2006; 27(6): 1272-1285, doi: 10.1183/09031936.06.00024004, indexed in Pubmed: 16772390.

6. Radzikowska E. Pulmonary Langerhans' cell histiocytosis in adults. Adv Respir Med. 2017; 85(5): 277-289, doi: 10.5603/ARM. a2017.0046, indexed in Pubmed: 29083024. 